\title{
Determinants of Risk Infection During Therapy with Anti TNF-Alpha Blocking Agents in Rheumatoid Arthritis
}

\author{
M. Benucci ${ }^{*}, 1$, G. Saviola ${ }^{2}$, P. Baiardi ${ }^{3}$, M. Manfredi ${ }^{4}$, P. Sarzi Puttini ${ }^{5}$ and Fabiola Atzeni ${ }^{5,6}$ \\ ${ }^{I}$ Rheumatology Unit Hospital S. Giovanni di Dio, Florence, Italy \\ ${ }^{2}$ Rheumatology Unit Maugeri Foundation, Mantua, Italy \\ ${ }^{3}$ Methodology Unit University of Pavia, Pavia, Italy \\ ${ }^{4}$ Laboratory of Immunology and Allergology Hospital S. Giovanni di Dio, Florence, Italy \\ ${ }^{5}$ Rheumatology Unit, L. Sacco University Hospital, Milan, Italy \\ ${ }^{6}$ Experimental Medicine, Queen Mary, University of London, London, UK
}

\begin{abstract}
The use of TNF-alpha antagonists (infliximab, etanercept, adalimumab) has changed the course of many rheumatic diseases including rheumatoid arthritis (RA). Since their approval, some questions regarding their safety including infections have been observed. The aim of the study was to evaluate the changes in cytokines levels and cells subsets in patients with RA during anti TNF blocking agents treatment and the possible effect on infections' development. We evaluated in 89 RA patients [39 treated with etanercept (ETN), 29 with adalimumab (ADA) and 21 with infliximab (IFN)] at baseline and after 6 months the following parameters: procalcitonin, ESR, CRP, cytokines as TNF, IL-6, IL-10, IL-8 and the TNF/IL-10 ratio, and peripheral mononuclear cells as CD3+, CD3+/CD4+, CD3+/CD8+, CD19+, CD3/CD16+/56+, CD14+HLADR+, CD20+, CD19+/CD38+. Peripheral mononuclear cells were detected by flow cytometric system Cytomics FC500 and cytokines circulating levels by a quantitative sandwich enzyme immunoassay technique (Human IL-8 Instant ELISAe Bioscience, Human IL-6 Instant ELISA e Bioscience, Human IL-10 Instant ELISAe Bioscience and Human TNF-a Quantikine immunoassay RD system). A lower reduction of CD14+HLADR+ in ADA group $54.6 \pm 10.4 \%$ vs ETA $48.4 \pm 15.7 \%$ vs INF $40.7 \pm 16.5 \%$, $\mathrm{p}<0.039$ was found. No differences in all three groups on peripheral mononuclear cells CD3+, CD3+/CD4+, CD3+/CD8+, CD19+, CD 20+, CD19+/CD38+, CD3-/CD16+/56+, and cytokine circulating levels were found. The number of infections at 6 months was: $10.3 \%$ in ADA group, $12.8 \%$ in ETN group and $19.04 \%$ in IFN group. A correlation was found between the reduction in CD14+HLADR+ cells and IFN treatment. Our data showed that the level of CD14+HLADR+ cells was reduced during therapy with IFN. ADA and ETN don't reduce lymphocyte populations and their subsets such as CD14+HLADR+ cells that play an important role host defence.
\end{abstract}

Keywords: Infections, TNF blocking agents, peripheral mononuclear cells.

\section{INTRODUCTION}

Rheumatoid arthrtis (RA) has terrible effects on a wide range of health outcomes, ranges from bone damage to musculoskeletal system. RA is associated with increased mortality and comorbidity related to different causes compared to the general population, including infections [1, 2]. Biologic therapies give the opportunity to target the precise immune and inflammatory pathway leads to improve the RA patients' outcomes and to reduce the associated comorbidity and mortality. The anti-TNF drugs were the first biologic agents to become available in management of RA patients who fail to respond to traditional non-biologic Disease-modifying antirheumatic drugs (DMARDs). However, TNF plays an important role in host defence [3, 4]; consequently the introduction of anti-TNF agents induce the

*Address correspondence to this author at the Rheumatology Unit, Azienda Sanitaria di Firenze, Ospedale S. Giovanni di Dio, Via Torregalli,3 50143 Florence, Italy; Tel: 0039-55-7192331; Fax: 0039-55-7192306;

E-mail: maubenucci@tiscali.it, maurizio.benucci@asf.toscana.it necessity to evaluate and understand the effect of this drugs on infections' risk. During bacterial infections as a sepsis different cytokines are secreted such as interleukin $1 \beta$ (IL$1 \beta$ ), interleukin 6 (IL-6), and tumor necrosis factor $\alpha$ (TNF$\alpha$ ), and high levels of these cytokines can induce an increased risk of mortality [5], but anti-cytokines treatment cannot improve the patients' survival [6]. Moreover, TNF release from macrophages play a crucial role in maintenance and formation of granuloma and in intracellular organisms the defence. Furthermore, TNF plays a role in leucocyte trafficking and Immune Complement (IC) clearance [7].

The aim of the study was to evaluate the changes in cytokines levels and cells subsets in patients with RA during anti TNF- $\alpha$ blocking agents treatment and the possible effect on infections' development.

\section{MATERIAL AND METHODS}

We evaluated 89 RA patients of a single centre that started a therapy with tumor necrosis factor $\alpha$ blocking agents in the period January 2008- December 2010, affected by RA according to the American College of Rheumatology 
(ACR) criteria 1998. We included 39 patients treated with etanercept (ETN), 29 with adalimumab (ADA) and 21 with infliximab (IFN) combined with corticosteroids (mean dosage 5,1 $\pm 2.1 \mathrm{mg}$ ) and methotrexate (MTX) (mean dosage $12.5 \mathrm{mg} /$ weekly, range $20-7.5 \mathrm{mg}$ ). The patients were evaluated at baseline and after 6 months for the following parameters: procalcitonin, erythrocyte sedimentation rate (ESR), C-Reactive Protein (CRP), cytokine such as tumour necrosis factor-alpha (TNF- $\alpha)$, IL6, IL-10, IL-8 and the TNF/IL-10 ratio, and peripheral mononuclear cells as CD3+, CD3+/CD4+, CD3+/CD8+, CD19+, CD3-/CD16+/56+, CD14+HLADR+, CD20+, CD19+/CD38+.

Peripheral mononuclear cells were detected by flow cytometric system Cytomics FC500( Beckman Coulter, Fullerton, CA, USA). We used the monoclonal antibodies CYTO-STAT tetra CHROME CD45FITC/CD4RD1, CD8ECD/CD3PC5，CD45FITC/CD56RD1/CD19ECD/CD3 PC5, CD19PE/CD38PC5/CD20FITC, CD14FITC/HLADRP $\mathrm{C} 5$ and the absolute count and the percentage of lymphocytes were detected. Cytokine circulating levels were evaluated by a quantitative sandwich enzyme immunoassay technique ( Human IL-8 Instant ELISAe Bioscience, Human IL-6 Instant ELISAe Bioscience, Human IL-10 Instant ELISAe Bioscience and Human TNFa Quantikine Immunoassay RD System).

The study was approved by the Ethics Committees and written informed consent was obtained from patients before inclusion in the study.

\section{Statistical Analysis}

Statistical analysis was performed using SPSS statistical package (SPSS Inc., Chicago, IL, USA; version 14.0, 2006). Quantitative variables were expressed as mean values and standard deviation. The associations between the quantitative variables were studied by means of correlation analysis, and those between the qualitative variables by means of contingency tables. Statistical significance was tested by ANOVA for parametric analysis and non parametric using the Kruskall-Wallis test. A two-tailed $\mathrm{P}$ value of $<0.05$ was considered statistically significant.

\section{RESULTS}

The clinical characteristics of the patients included in the study are reported in Table $\mathbf{1}$.

No difference in baseline values among the three treated group on mononuclear cells and cytokines was detected (Tables I and 2) We evaluated at baseline the normal range of peripheral mononuclear cells in donors health age matched. A lower reduction of CD14+HLADR+ in ADA group 54.6 $\pm 10.4 \%$ vs ETA $48.4 \pm 15.7 \%$ vs INF $40.7 \pm 16.5 \%$, $\mathrm{p}<0.039$ was found after twenty-four weeks of treatment with anti-TNF agents. No differences in all three groups on peripheral mononuclear cells $\mathrm{CD} 3+, \mathrm{CD} 3+/ \mathrm{CD} 4+$, $\mathrm{CD} 3+/ \mathrm{CD} 8+, \mathrm{CD} 19+, \mathrm{CD} 20+, \mathrm{CD} 19+/ \mathrm{CD} 38+, \mathrm{CD} 3-$ $/ \mathrm{CD} 16+/ 56+$ and cytokine circulating levels was found after treatment with anti-TNFa agents (Tables $\mathbf{2}$ and $\mathbf{3}$ ). The number of infections at 6 months was: $10.3 \%$ in ADA group ( 2 in respiratory tract, 1 in urinary tract), 12.8\% in ETN group ( 3 in respiratory tract, 2 in urinary tract) and $19.04 \%$ ( 3 in respiratory tract, 1 herpes zoster) in IFN group. No hospitalization was observed in the three groups.

No correlation between the number of infections in the group of INF and ETN and ADA was found.

\section{DISCUSSION}

In this paper we have evaluated the role of the integrity of immune system and the variations under therapy with three different TNF $\alpha$ blocking agents in RA patients during the first six months of treatment. RA patients have been recognised to be at increased risk of infection for several decades [8]. Given the involvement of CD14+ in disease, including sepsis and chronic heart failure, the discovery of signal transduction pathways activated exclusively via CD14+ is an important step towards the development of potential treatments involving interference with CD14+ functions [9].

In human monocytes/macrophages pre-incubated with TNF-R1-expressing human endothelial cells, reverse signalling through transmembrane TNF-a mediated LPS resistance as indicated by the down-regulation of LPSinduced soluble TNF-a and IL-6 as well as IL-1 and -10 [10]. Pre-treatment with soluble TNF-R1 for inducing reverse

Table 1. The Clinical Characteristic of the Patients Included in the Study

\begin{tabular}{|l|c|c|c|}
\hline & Etanercept Group (39 pts) & Adalimumab Group (29 pts) & Infliximab Group (21 pts) \\
\hline \hline Age mean years & $59.6 \pm 9.8$ & $58.7 \pm 10.6$ & $60.1 \pm 9.3$ \\
\hline Disease mean & $8.4 \pm 3.2$ & $8.2 \pm 4.2$ & $8.5 \pm 4.1$ \\
\hline Female/Male & $33 / 6$ & $25 / 4$ & $19 / 2$ \\
\hline Corticosteroid dose $\mathbf{~ m g}$ & $5.2 \pm 2.1$ & $4.8 \pm 2.2$ & $4.9 \pm 2.2$ \\
\hline Methotrexate dose $\mathbf{~ m g / w ~}$ & $11.5 \pm 3.6$ & $12.6 \pm 2.5$ & $12.7 \pm 2.3$ \\
\hline RF positive & $67 \%$ & $68 \%$ & $66 \%$ \\
\hline Anti CC-P positive & $83 \%$ & $81 \%$ & $80 \%$ \\
\hline DAS28 & $4.8 \pm 1.4$ & $4.7 \pm 1.6$ & $4.6 \pm 1.5$ \\
\hline ESR $\mathbf{~ m m / h ~}$ & $49.3 \pm 12.5$ & $51.2 \pm 9.6$ & $51.6 \pm 9.9$ \\
\hline CRP $\mathbf{~ m g / d l ~}$ & $3.2 \pm 1.4$ & $3.3 \pm 1.6$ & $3.1 \pm 1.8$ \\
\hline
\end{tabular}


Table 2. The Values of Cytokines at Baseline and After 6 Months of Anti-TNFa Treatment

\begin{tabular}{|c|c|c|c|c|c|c|c|}
\hline Cytokines Value & $\begin{array}{l}\text { ADA Group } \\
\text { Week } 0\end{array}$ & $\begin{array}{l}\text { ETN Group } \\
\text { Week } 0\end{array}$ & $\begin{array}{l}\text { IFN Group } \\
\text { Week } 0\end{array}$ & $\begin{array}{l}\text { ADA Group } \\
\text { Week } 24\end{array}$ & $\begin{array}{l}\text { ETN Group } \\
\text { Week } 24\end{array}$ & $\begin{array}{l}\text { IFN Group } \\
\text { Week } 24\end{array}$ & P Value \\
\hline $\mathrm{TNFa} \mathrm{pg} / \mathrm{ml}$ & $33.1 \pm 12.3$ & $33.1 \pm 12.3$ & $34.4 \pm 12.6$ & $86.7 \pm 70.3$ & $171.4 \pm 69.4$ & $182.5 \pm 47.4$ & NS \\
\hline IL-6 pg/ml & $6.7 \pm 3.5$ & $7.6 \pm 2.9$ & $7,1 \pm 3.1$ & $8.8 \pm 2.7$ & $4.7 \pm 3.5$ & $6.4 \pm 4.3$ & NS \\
\hline $\mathrm{IL}-10 \mathrm{pg} / \mathrm{ml}$ & $3.2 \pm 1.5$ & $3.6 \pm 2.1$ & $2.5 \pm 1.6$ & $3.9 \pm 2.8$ & $2.5 \pm 2.3$ & $5.5 \pm 5.1$ & NS \\
\hline IL-8 pg/ml & $4.8 \pm 2.1$ & $3.7 \pm 2.1$ & $4.1 \pm 1.9$ & $3.03 \pm 2.1$ & $5.8 \pm 4.1$ & $4.7 \pm 2.9$ & NS \\
\hline TNFa/IL10 ratio & $78.9 \pm 11.7$ & $54.1 \pm 12.7$ & $54.2 \pm 13.9$ & $78.9 \pm 11.7$ & $54.1 \pm 12.7$ & $54.2 \pm 13.9$ & NS \\
\hline
\end{tabular}

Table 3. The Values of Lymphocytes at Baseline and After 6 Months of Anti-TNFa Treatment

\begin{tabular}{|c|c|c|c|c|c|c|c|c|c|}
\hline Cells & $\begin{array}{l}\text { ADA Group } \\
\text { Week } 0\end{array}$ & $\begin{array}{l}\text { ETN Group } \\
\text { Week } 0\end{array}$ & $\begin{array}{l}\text { IFN Group } \\
\text { Week } 0\end{array}$ & $\begin{array}{c}\text { Normal Value in } \\
\text { Donors Age Matched }\end{array}$ & $\begin{array}{c}\mathbf{P} \\
\text { Value }\end{array}$ & $\begin{array}{l}\text { ADA Group } \\
\text { Week } 24\end{array}$ & $\begin{array}{l}\text { ETN Group } \\
\text { Week } 24\end{array}$ & $\begin{array}{l}\text { IFN Group } \\
\text { Week } 24\end{array}$ & $\begin{array}{c}P \\
\text { Value }\end{array}$ \\
\hline $\mathrm{CD} 3+$ & $1734 \pm 657$ & $1725 \pm 688$ & $1724 \pm 637$ & $1100-1700$ & NS & $1838 \pm 632$ & $1653 \pm 736$ & $1645 \pm 624$ & NS \\
\hline $\mathrm{CD} 3+/ \mathrm{CD} 4+$ & $1734 \pm 657$ & $1134 \pm 317$ & $1158 \pm 366$ & $650-1400$ & NS & $1250 \pm 496$ & $1065 \pm 562$ & $1067 \pm 446$ & NS \\
\hline $\mathrm{CD} 3+/ \mathrm{CD} 8+$ & $470 \pm 210$ & $445 \pm 218$ & $480 \pm 205$ & $320-900$ & NS & $520 \pm 230$ & $489 \pm 223$ & $534 \pm 321$ & NS \\
\hline CD19+ & $268 \pm 89$ & $245 \pm 92$ & $259 \pm 91$ & $200-400$ & NS & $273 \pm 143$ & $261 \pm 202$ & $255 \pm 174$ & NS \\
\hline CD19+/CD38+ & $234 \pm 143$ & $223 \pm 133$ & $214 \pm 163$ & $150-400$ & NS & $240 \pm 155$ & $109 \pm 74$ & $79 \pm 15$ & NS \\
\hline $\mathrm{CD} 16+/ 56+$ & $211 \pm 72$ & $217 \pm 68$ & $213 \pm 67$ & $200-400$ & NS & $219 \pm 87$ & $211 \pm 54$ & $210 \pm 45$ & NS \\
\hline CD14+HLADR+\% & $57 \pm 12$ & $55 \pm 14$ & $59 \pm 12$ & $50-90$ & NS & $54.6 \pm 10.4$ & $48.4 \pm 15.7$ & $40.7 \pm 16.5$ & $<0.039$ \\
\hline CD14+HLADR+ & $345 \pm 213$ & $335 \pm 223$ & $349 \pm 209$ & $300-400$ & NS & $326 \pm 214$ & $311 \pm 230$ & $246 \pm 78$ & $<0.05$ \\
\hline
\end{tabular}

signalling through transmembrane TNF-a sensitized human monocyte cell line U937 cells to soluble TNF-a-induced activation, whereas stimulation of transmembrane TNF-a after soluble TNF-a-induced activation of U937 cells reduced mRNA stability of IL-1b and IL-8 [11]. In contrast to these findings that transmembrane TNF-a may inhibit sustained activation of monocytes, transmembrane TNF-a played a positive role in the activation of monocytes. Ligation of transmembrane TNF-a on monocytes by TNF-R2 on $\mathrm{T}$ cells or soluble TNF-R2: Ig receptor construct (etanercept) induced TNF-a production due to outside-toinside signalling through transmembrane TNF-a [12].

The effects of three TNF $\alpha$ blocking agents are different on immune sistem [13]. Infliximab binds to both monomer and trimer forms of soluble TNF-a, whereas etanercept binds only to the trimer form [14]. Infliximab formed stable complexes with soluble TNF-a, while etanercept formed relatively unstable complexes. Each infliximab molecule is capable of binding to two TNF-a molecules, and up to three infliximab molecules can bind to each TNF-a homotrimer. In contrast, etanercept is supposed to form $1: 1$ complex with the TNF-a trimer [15].

All the reports were in agreement that infliximab and adalimumab induced CDC (cytotoxicity dependent complement) much more potently than etanercept. In contrast, certolizumab pegol did not have any CDC activity [15], which reflects its absence of the Fc portion of IgG1. It is thus difficult for etanercept to make a membrane attack complex of complement proteins (C5b-C9) for CDC at least in vitro.
When activated human peripheral blood mononuclear cells were studied as target cells, none of these three antiTNF agents induced CDC [16], Infliximab, adalimumab and etanercept showed similar antibody dependent cell-mediated cytotoxicity (ADCC) activitiy using mTNF-transfected Jurkat $\mathrm{T}$ cells as target [17], while infliximab and adalimumab showed much more potent ADCC than etanercept in NS0 cells [15]. The discrepancy in etanerceptinduced ADCC is not clear, but may be explained by the different experimental conditions, such as difference in the species of target cell, in the expression level of transmembrane TNF-a. Both mAbs and etanercept weakly bound to Fcg receptors in the absence of soluble TNF-a, but in the presence of soluble TNF-a, there was a marked increase in binding only by mAbs infliximab and adalimumab [18]. As for infliximab, induction of both CDC and ADCC has been reported by others [19].

Outside-to-inside signalling (reverse signalling) is a novel function of anti-TNF agents for the inhibition of TNFa-producing cells, which is mediated by mechanisms independent of CDC and ADCC [17-20]. Infliximab and adalimumab, but not etanercept, induced apoptosis and cell cycle G0/G1 arrest upon binding to transmembrane TNF-aexpressing Jurkat T cells. Cross-linking of etanercept bound to the cell-surface transmembrane TNF-a resulted in increased apoptosis [20], which indicates that multimer formation with $\mathrm{mAbs}$ and transmembrane TNF-a may be essential for the initiation of the subsequent intracellular signals. IL-10 production was induced by infliximab, but not by etanercept, in transmembrane TNF-alpha-expressing 
Jurkat T cells [20]. We did't evaluate in our study a subgroup of patients with RA without therapy with antiTNF, but previous study has shown that RA patients have a nearly 2 -fold increased risk for infection compared with the age and sex matched control subjects for accelerated immunosenescence particularly of $\mathrm{T}$ cells [21]. Our data showed that no differences in all three groups on peripheral mononuclear cells CD3+, CD3+/CD4+, CD3+/CD8+, CD19+, CD20+, CD19+/CD38+, CD3-/CD16+/56+ and cytokine circulating levels were found after treatment with anti-TNF agents but the levels of CD14+HLADR+ markers of monocytes were reduced during therapy with IFN in the first six months and this could be a parameter of possible correlation with more infection that we have in this subgroup of patients with RA. Our data reveal that Adalimumab and Etanercept don't reduce lymphocyte population and subsets such as CD14+HLADR+ cells that have an important role against infections. Expression of class II major histocompatibility complex (MHC) on monocytes is a prerequisite for effective antigen presentation and processing, an important component of the immune response to infection [22]. It has been reported that the level of monocyte class II expression may identify patients who go on to develop infective complications following trauma [23]. Membrane CD14 (mCD14), a 55-kD glycoprotein on the cell membrane of monocytes and polymorphonuclear cells, plays a key role in transmitting LPS signals intracellularly and ultimately activating tumor necrosis factor (TNF)-a production [24]. A animal model study showed that a monocyte mCD14 and HLA-DR expression decreased might contribute to endotoxin tolerance and a rapid reduction on LPS responsiveness [25]. The high reduction in patients in treatment with INF could be explained by the major effects of this monoclonal antibody on ADC and CDC. Moreover, it has been suggested that monoclonal antibodies carry a higher risk than ETN because of their different effects on different cells including this subset of monocytes [26].

A review of observational research designs has revealed a higher risk of infections in the first few months of antiTNF treatment [27], followed by a progressive reduction and our finding confirm this data suggesting that these cells can play a role.

In the literature the data on infections induced by antiTNF agents were extrapolated by the Registers that involve a large amount of the patients [28,29]. A recent paper on a large cohort of 16.506 patients treated with anti-TNF showed $7,1 \%$ of serious infections most of which were pneumonia, skin and soft tissue infections [30].

Moreover, this is a pilot study focused on researching of some biomarkers associated with the infection risk that can help in clinical practice to prevent this complications.

Further studies are required to confirm these data and to define precise biomarkers for assessing and managing infections in RA patients treated with anti-TNF agents involving a large cohort of patients.

\section{ACKNOWLEDGEMENTS}

None declared.

\section{CONFLICT OF INTEREST}

None declared.

\section{REFERENCES}

[1] Doran MF, Crowson CS, Pond GR, O'Fallon WM, Gabriel SE. Frequency of infection in patients with rheumatoid arthritis compared with controls: a population-based study. Arthritis Rheum 2002; 46: 2287-93.

[2] Symmons DP, Jones MA, Scott DL, Prior P. Longterm mortality outcome in patients with rheumatoid arthritis: early presenters continue to do well. J Rheumatol 1998; 25: 1072-7.

[3] Aggarwal BB. Signalling pathways of the TNF superfamily: a double-edged sword. Nat Rev Immunol 2003; 3: 745-56.

[4] Feldmann M, Maini RN. Anti-TNF alpha therapy of rheumatoid arthritis: what have we learned? Annu Rev Immunol 2001; 19: 163 96.

[5] Hack CE, Aarden LA, Thijs LG. Role of cytokines in sepsis. Adv Immunol 1997; 66: 95-101.

[6] Netea MG, van der Meer JW, van Deuren M, Kullberg BJ. Proinflammatory cytokines and sepsis syndrome: not enough, or too much of a good thing? Trends Immunol 2003; 24: 254-8.

[7] Alves-Rosa MF, Palermo MS, Isturiz MA. Enhancement of immune complex clearance by TNF-alpha in a murine model. Clin Immunol Immunopathol 1998; 89: 214-21.

[8] Galloway GB, Hyrich KL, Mercer LK, et al. Anti-TNF therapy is associated with an increased risk of serious infections in patients with rheumatoid arthritis especially in the first 6 months of treatment: updated results from the British Society for Rheumatology Biologics Register with special emphasis on risks in the elderly. Rheumatology(Oxford) 2010; 50(1): 124-31.

[9] Zanoni I, Ostuni R, Capuano G, et al. CD14 regulates the dendritic cell life cycle after LPS exposure through NFAT activation. Nature 2009; 460(7252): 264-8.

[10] Eissner G, Kirchner S, Lindner $\mathrm{H}$ et al. Reverse signaling through transmembrane TNF confers resistance to lipopolysaccharide in human monocytes and macrophages. J Immunol 2000; 164: 61938.

[11] Xin L, Wang J, Zhang $\mathrm{H}$ et al. Dual regulation of soluble tumor necrosis factor-a induced activation of human monocytic cells via modulating transmembrane TNF-a-mediated "reverse signaling". Int J Mol Med 2006; 18: 885-92.

[12] Rossol M, Meusch U, Pierer $\mathrm{M}$ et al. Interaction between transmembrane TNF and TNFR1/2 mediates the activation of monocytes by contact with T cells. J Immunol 2007; 179: 4239-48.

[13] Horiuchi T, Mitoma H, Harashima S, TsukamotoH, Shimoda T Transmembrane TNF-a: structure, function and interaction with anti-TNF agents. Rheuamtology(Oxford) 2010; 49: 1215-28

[14] Tracey D, Klareskog L, Sasso EH, Salfeld JG, Tak PP. Tumor necrosis factor antagonist mechanisms of action: a comprehensive review. Pharmacol Ther 2008; 117: 244-79.

[15] Nesbitt A, Fossati G, Bergin M et al. Mechanism of action of certolizumab pegol (CDP870): in vitro comparison with other antitumor necrosis factor alpha agents. Inflamm Bowel Dis 2007; 13: 1323-32.

[16] Kaymakcalan Z, Sakorafas P, Bose S et al. Comparisons of affinities, avidities, and complement activation of adalimumab, infliximab, and etanercept in binding to soluble and membrane tumor necrosis factor. Clin Immunol 2009; 131: 308-16.

[17] Mitoma $\mathrm{H}$, Horiuchi $\mathrm{T}$, Tsukamoto $\mathrm{H}$ et al. Mechanisms for cytotoxic effects of anti-TNF agents on transmembrane TNFexpressing cells: comparison among infliximab, etanercept and adalimumab. Arthritis Rheum 2008; 58: 1248-57.

[18] Arora T, Padaki R, Liu L et al. Differences in binding and effector functions between classes of TNF antagonists. Cytokine 2009; 45: 124-31.

[19] Scallon BJ, Moore MA, Trinh H, Knight DM, Ghrayeb J. Chimeric anti-TNF-alpha monoclonal antibody cA2 binds recombinant transmembrane TNF-alpha and activates immune effector functions. Cytokine 1995; 7: 251-9.

[20] Mitoma H, Horiuchi $\mathrm{T}$, Hatta $\mathrm{N}$ et al. Infliximab induces potent anti-inflammatory responses by outside-to-inside signals through transmembrane TNF-a. Gastroenterology 2005; 128: 376-92. 
[21] Goronzy JJ, Weyand CM. Rheumatoid arthritis. Immunol Rev 2005; 204: 55-73

[22] Hershman MJ, Cheadle WG, Wellhausen SR, et al. Monocyte HLA-DR antigen expression characterizes clinical outcome in trauma patient. Br J Surg 1990; 77: 204-7.

[23] Cheadle WG, Hershman MJ, Wellhausen SR, Polk HC Jr. HLADR antigen expression on peripheral blood monocytes correlates with surgical infection. Am J Surg 1991; 161: 639-45.

[24] Ziegler-Heitbrock HW, Ulevitch RJ. CD14: cell surface receptor and differentiation marker. Immunol Today 1993; 14: 121-5.

[25] Haziot A, Ferrero E, Kontgen F, et al. Resistance to endotoxin shock and reduced dissemination of gram-negative bacteria in CD14-deficient mice. Immunity 1996; 4: 407-14.

[26] Wallis RS, Ehlers S. Tumor necrosis factor and granuloma biology: explaining the differential infection risk of etanercept and infliximab. Semin Arthritis Rheum 2005; 34 (Suppl 1): 34-8.
[27] Askling J, Dixon W. The safety of anti-tumour necrosis factor therapy in rheumatoid arthritis. Curr Opin Rheumatol 2008; 20: 138-44.

[28] Favalli EG, Desiati F, Atzeni F, et al. Serious infections during anti-TNFalpha treatment in rheumatoid arthritis patients. Autoimmun Rev 2009; 8: 266-73.

[29] Dixon WG, Watson K, Lunt K, Hyrich KL. British Society for Rheumatology Biologics Register Control Centre Consortium, Silman AJ, Symmons DPM. Rates of serious infection, including site-specific and bacterial intracellular infection, in rheumatoid arthritis patients receiving anti-tumor necrosis factor therapy. Arthritis Rheum 2006; 54: 2368-76.

[30] Grijalva CG, Chen L, Delzell E, et al. Initiation of tumor necrosis factor- $\alpha$ antagonists and the risk of hospitalization for infection in patients with autoimmune diseases. JAMA 2011; 306(21): 2331-9.

Received: September 20, 2011

Revised: January 13, 2012

Accepted: March 19, 2012

(C) Benucci et al.; Licensee Bentham Open.

This is an open access article licensed under the terms of the Creative Commons Attribution Non-Commercial License (http://creativecommons.org/licenses/by$\mathrm{nc} / 3.0 /$ ) which permits unrestricted, non-commercial use, distribution and reproduction in any medium, provided the work is properly cited. 